Research Article

\title{
Prevalence and risk factors of inguinal hernia: a study in a semi-urban area in Rayalaseema, Andhra Pradesh, India
}

\author{
G. Balamaddaiah, S. V. Rama Mohan Reddy*
}

Department of Surgery, Viswabharthi Medical College, Kurnool, Andhra Pradesh, India

Received: 23 June 2016

Accepted: 02 July 2016

\section{*Correspondence:}

Dr. S. V. Rama Mohan Reddy,

E-mail: siruparammohan@yahoo.co.in

Copyright: () the author(s), publisher and licensee Medip Academy. This is an open-access article distributed under the terms of the Creative Commons Attribution Non-Commercial License, which permits unrestricted non-commercial use, distribution, and reproduction in any medium, provided the original work is properly cited.

\begin{abstract}
Background: The protrusion from the abdominal cavity through the inguinal canal is called inguinal hernia. Although several hypotheses regarding the etiology of inguinal hernia have been proposed, large-scale data on the occurrence of inguinal hernia may provide further understanding to the pathophysiology of inguinal hernia development. This study was conducted with the intention of identifying the various types of inguinal hernia observed in our area as well as their risk factors.

Methods: All the study subjects had come to the hospital with complaints of groin swelling with or without pain. The patient was palpated at each groin to observe if there was a visible and clearly palpable hernia, a palpable impulse or a previous operational scar. Details of the hernia, such as the type of hernia, primary or recurrent were also noted.

Results: Out of the 212 patients, $79.2 \%$ patients were males and $20.8 \%$ were females and the commonest age group was 31-60 years. $74.5 \%$ of the cases were primary inguinal hernia while $25.5 \%$ were recurrent hernia. Period of swelling was less than one year for majority of the patients, while the least of them had swelling for more than 2 years. The most common cause for the presence of hernia was lifting heavy objects in $52.4 \%$ and improper bowel movements $(46.7 \%)$.

Conclusions: These type of studies need to be conducted in every geographical area so that it can be helpful for future studies in prediction of the prevalence of inguinal hernias.
\end{abstract}

Keywords: Inguinal hernias, Primary hernia, Recurrent hernia, Prevalence, Risk factors

\section{INTRODUCTION}

A hernia occurs when an organ of the body pushes itself through an opening in the muscle or tissue that is supposed to hold it in place. This type of hernia is most common in the abdominal region. This opening or the orifice is a defect in the innermost layer of the abdomen and the hernia is outpouch of the peritoneum. Abdominal wall hernias only occur in certain areas namely, where aponeurosis and fascia are devoid of the protecting support of striated muscle. These may be acquired through muscular atrophy, surgery or trauma. Therefore the common sites of hernia include the groin, umbilicus and the linea alba. ${ }^{1}$
The protrusion from the abdominal cavity through the inguinal canal is called inguinal hernia. This is the most common type of hernia and affects chiefly men. ${ }^{2}$ If is often said to be associated with aging and repeated strain to the abdominal muscles. The prevalence of the abdominal wall hernia is estimated to be $1.7 \%$ for all ages and $4 \%$ of those who are over 45 years of age. The inguinal hernias account for $75 \%$ of the abdominal hernias with a life time risk of $27 \%$ in males and $3 \%$ in the females. ${ }^{3}$

Repair of the inguinal hernias is one of the most common operations in the general surgery, with rates ranging from 10 per 100,000 of the population in England and about 28 per 100000 in the United States. ${ }^{4}$ Ninety five per cent of 
patients presenting to primary care are male, and in men the incidence rises from 11 per 10000 person years aged 16-24 years to 200 per 10000 person years aged 75 years or above. ${ }^{5}$

The well known risk factors and causes of the inguinal hernias have been reported as increased abdominal pressure, pre-existing weakness of abdominal muscles, straining during defecation, heavy lighting of weights, obesity, pregnancy etc. Although several hypotheses regarding the etiology of inguinal hernia have been proposed, large-scale data on the occurrence of inguinal hernia may provide further understanding to the pathophysiology of inguinal hernia development. ${ }^{6}$

This study was conducted with the intention of identifying the various types of inguinal hernia observed in our area as well as their risk factors.

\section{METHODS}

This study was conducted as an observational study at Viswabharathi Medical College on 212 adults who had come to the surgery outpatient department for inguinal hernia repair or recurrence from Feb 2014to March 2016.

All the study subjects had come to the hospital with complaints of groin swelling with or without pain. After obtaining informed consent from all the participants, demographic details were taken by means of a questionnaire, which included the patient's identity, family history, life style habits, nature of job, duration of swelling, cough, constipation and comorbidities.

A thorough clinical examination was performed by the surgeon and the nature of the examination, privacy and confidentiality was explained to the patient. Details of the hernia, such as the type of hernia, primary or recurrent, time gap between present and the primary operation, nature of mesh used, time of recurrence and nature of the final repair were also noted.

The patient was palpated at each groin to observe if there was a visible and clearly palpable hernia, a palpable impulse or a previous operational scar. Clearly visible hernias were identified by a visible lump. If its neck was continuous with the inguinal canal or directed backwards into the abdomen, it was diagnosed as a palpable hernia. If there was no visible lump, the scrotum was invaginated by the little finger to reach the external ring, and the subject was asked to cough, in order to determine whether there was a palpable impulse. Scarring at the site was taken as recurrence of hernia.

\section{RESULTS}

Out of the 212 patients, $168(79.2 \%)$ patients were males and $44(20.8 \%)$ were females. $35.8 \%$ of the patients were aged between 46-60 years, which was the commonest age group, followed by 31-45 years with $63(29.7 \%)$ of the patients (Table 1).

Table 1: Agewise distribution of the patients.

\begin{tabular}{|lll|}
\hline Age & Number & Percentage \\
\hline $18-30$ & 8 & $3.8 \%$ \\
\hline $31-45$ & 63 & $29.7 \%$ \\
\hline $46-60$ & 76 & $35.8 \%$ \\
\hline $61-75$ & 44 & $20.8 \%$ \\
\hline$>75$ & 21 & $9.9 \%$ \\
\hline
\end{tabular}

$158(74.5 \%)$ of the cases were primary inguinal hernia while $54(25.5 \%)$ were recurrent hernia (Figure 1).

— Primary Inguinal Hernia $\quad$ Recurrent Hernia

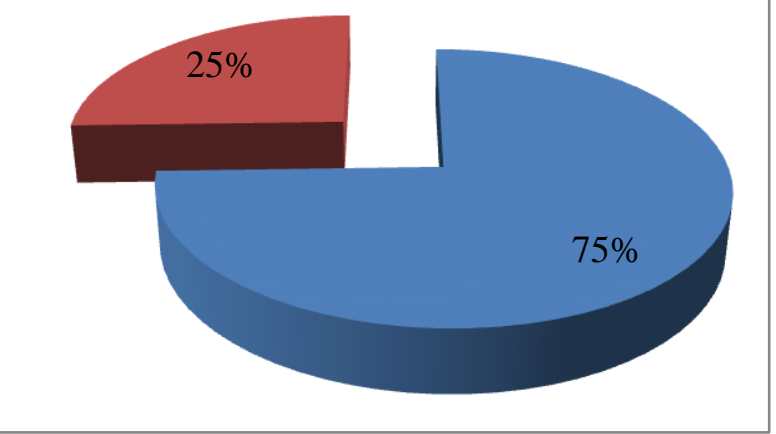

Figure 1: Type of hernia.

Period of swelling was less than one year for majority of the patients, while the least of them had swelling for more than 2 years (Table 2).

Table 2: Period of swelling.

\begin{tabular}{|lll|}
\hline Period of swelling & Number & Percentage \\
\hline$<1$ years & 121 & $57.1 \%$ \\
\hline $1-2$ years & 66 & $31.1 \%$ \\
\hline$>2$ years & 25 & $11.8 \%$ \\
\hline
\end{tabular}

Primary inguinal hernia was seen in 122 of the males, which accounted for $77.2 \%$ of the primary hernias diagnosed, while in females, the incidence of primary hernias was $36(22.8 \%)$. Recurrent hernias were seen in 46 males accounting for $85.2 \%$ of the recurrent cases while it was $14.8 \%$ in females (Table 3 ).

The most common side where the hernia was observed was on the right side with 101 cases $(47.6 \%)$, followed by the left side with 71 patients $(33.5 \%) .40$ (18.9\%) patients had inguinal hernia on both the sides (bilateral) (Figure 2). 
Table 3: Prevalence of primary and recurrent hernia among men and women.

\begin{tabular}{|c|c|c|c|}
\hline & $\begin{array}{l}\text { Primary } \\
\text { hernia }(\%)\end{array}$ & $\begin{array}{l}\text { Recurrent } \\
\text { hernia (\%) }\end{array}$ & Total (\%) \\
\hline Males & $122(77.2 \%)$ & $46(85.2 \%)$ & $168(79.2)$ \\
\hline Females & $36(22.8 \%)$ & $8(14.8 \%)$ & $44(20.8 \%)$ \\
\hline Total & $158(74.5 \%)$ & $54(25.5 \%)$ & $212(100 \%)$ \\
\hline
\end{tabular}

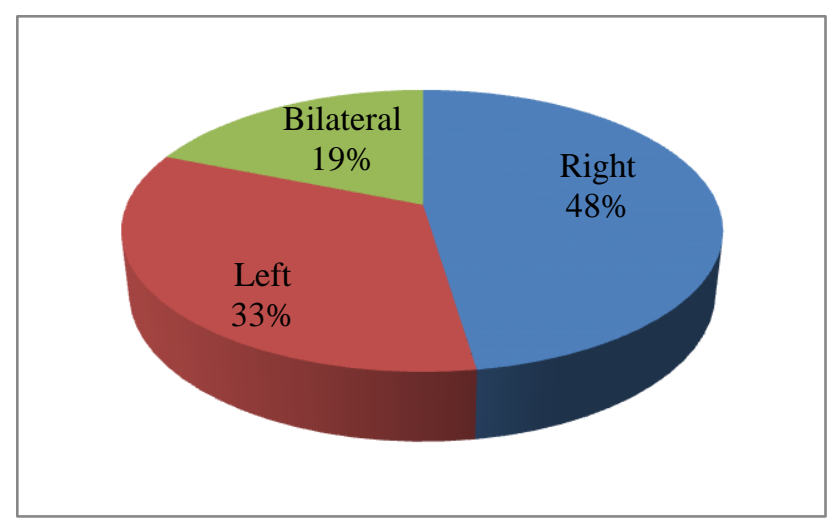

Figure 2: Side of hernia.

The most common cause for the presence of hernia was lifting heavy objects in $111(52.4 \%)$ and improper bowel movements, largely which was constipation, seen in $99(46.7 \%)$ of the patients. $67(31.6 \%)$ had diabetes and $88(41.5 \%)$ had chronic Obstructive Pulmonary Disease. $81(8.2 \%)$ of the patients were alcoholics and $79(37.3 \%)$ of them were smokers (Table 4).

Table 4: Risk factors for inguinal hernia.

\begin{tabular}{|lll|}
\hline Risk factors & Number & Percentage \\
\hline Family history & 31 & $14.6 \%$ \\
\hline Smoking & 79 & $37.3 \%$ \\
\hline Alcoholism & 81 & $38.2 \%$ \\
\hline Lifting heavy objects & 111 & $52.4 \%$ \\
\hline COPD & 88 & $41.5 \%$ \\
\hline Bowel disturbances & 99 & $46.7 \%$ \\
\hline Old Age (>60 years) & 63 & $29.7 \%$ \\
\hline Ascitis & 29 & $13.7 \%$ \\
\hline Diabetes & 67 & $31.6 \%$ \\
\hline $\begin{array}{l}\text { Benign hypertrophy of } \\
\text { prostate }\end{array}$ & 14 & $6.6 \%$ \\
\hline Urethral strictures & 34 & $16 \%$ \\
\hline Unknown & 12 & $5.7 \%$ \\
\hline
\end{tabular}

\section{DISCUSSION}

A hernia occurs when an internal part of the body pushes through a weakness in the muscle or surrounding tissue wall. In many cases, hernias cause no or very few symptoms, although you may notice a swelling or lump in your tummy (abdomen) or groin. The lump can often be pushed back in, or will disappear when you lie down.
Coughing or straining may make the lump appear. Hernia is considered a complication of PD. The pathophysiology is based on the concept of increased abdominal pressure (mechanical effect) affecting a weak abdominal wall. ${ }^{7}$

In the present study, the most common affected age group was $46-60$ years followed by $30-45$ years. This was in concordance with a study by Balram et al, wherein, 42-50 years age group was the most common age group in Jalaun, Uttar Pradesh. ${ }^{8}$ This was similar to other studies such as Sayanna et al and Basu et al. ${ }^{9,10}$ A much younger age group was shown to have more prevalence of hernia in a study by Kumar et al, 20-49 age group seemed to have almost $0 \%$ of the burden. Hernia was seen to be less common among the adolescents. ${ }^{6}$ Bimodal peaking among the young and the elderly was observed in some other studies. ${ }^{11}$

In present study, primary hernia was more common than recurrent hernia. Both primary and recurrent hernia was more common in males than in females. The preponderance of males to females was also seen in other studies such as Balram et al, Sayanna et al, Gulzar et al and Ruhl et al. ${ }^{8,9,12,13}$ This preponderance of hernia in males was attributed to the fact that here was involvement of more strenuous exercises and lifting of weights by them and the anatomical differences between the two. ${ }^{8}$

Most of the patients (57.1\%) had swelling for less than a year before they came to the OP. This was in accordance to a study by Kumar et al wherein $68 \%$ of the patients had swelling for less than 1 year. ${ }^{6}$ This is because most of the patients do not seek medical attention till the pain or discomforts limits their daily activity. In most of the cases, the hernia is reducible i.e. pushed back into the abdomen when lying down or putting pressure on it. In some cases irreducible hernia occur which cause complications such as obstruction, incarceration and strangulation.

$48 \%$ of the patients had right side hernia followed by left. Bilateral hernia was seen in the least number of patients. Similar was the case in the study by Balram et al where the right side hernia was the commonest. $6.9 \%$ of the patient in his study showed bilateral hernia. ${ }^{8}$ Other workers also reported similar results. ${ }^{14-16}$ This dominance was similar in both the genders equally. The cause for the right side predominance was said to be due to late fall down of the testis and more frequent failure of closure of right processus vaginalis. ${ }^{17,18}$

The main risk factor in present study was lifting of heavy weights $(52.4 \%)$ followed by bowel disturbance which accounted for $46.7 \%$ of the cases. Smoking and diabetes were other common reasons for hernia. Hernia due to heavy object lifting was common in a similar study by Kumar R et al, $48.8 \%$ had hernia due to lifting heavy objects, with smoking habits and chronic cough being the other common risk factors. The occupation of many of 
the men was farming, hauling construction, lifting weights at the factory etc. These factors increase the abdominal pressure during cough or straining, which further increase the risk of inguinal hernia. A study in USA reported that inguinal hernia was associated with older age, obesity, greater height, chronic cough or rural residence. $^{19}$

Family history was another important factor contributing to occurrence of hernia in patients. This was concurred by others such as Lau et al and Junge et al, who also predicted hernia if a family member previously had it. ${ }^{20,21}$

Diet, diseases and personal habits of the patients are known to affect and cause recurrence of inguinal hernia. ${ }^{22}$

\section{CONCLUSION}

The study shows a predominance of males over females in the middle age group in the incidence of primary and recurrent inguinal hernia. Right side occurrence is more common and the main risk factors are straining or lifting heavy objects and irregular bowel movements.

These type of studies need to be conducted in every geographical area so that it can be helpful for future studies in prediction of the prevalence of inguinal hernias.

\section{Funding: No funding sources}

Conflict of interest: None declared

Ethical approval: The study was approved by the institutional ethics committee

\section{REFERENCES}

1. Rao G, Rao A, Pujara N, Pujara P, Patel S. Prevalence of hernia among fishermen population in Kutch district. India . National J Integrated Res Med. 2015;6(4):44-51.

2. Chiow AKH, Chong KC, Tan SM. Inguinal hernias: a current review of an old problem. Proceedings Singapore Healthcare. 2010;19(3):202-11.

3. Kingsnorth A, Leblanc K. Hernias: inguinal and incisional. Lancet. 2003;362:1561-71.

4. Devlin HB. Trends in hernia surgery in the land of Astley Cooper. In: Soper NJ, ed. Problems in general surgery. $12^{\text {th }}$ edition. Philadelphia,PA: Lippincott-Raven;1995:85-92.

5. Chow A, Purkayastha S, Athanasiou T, Tekkis P, Darzi A. Inguinal hernia. British Med J Clin Evid. 2007;4:1-20.

6. Kumar BRK, Madhusoodhanan N, Balaji A, Poornima MA. Prevalence and risk factors of inguinal hernia-a hospital based observational study. Int J Med Appl Sc. 2014;3(4):191-8.
7. Garcia MA, Rodriguez CR, Ruiz VV, Hernandez FJC, Ruiz EF, Gallego JMV et al. Prevalence and management of hernias in peritoneal dialysis patients. Perit Dial Int. 2006;26:198-202.

8. Balram. Prevalence of inguinal hernia in Bundelkhand region of India. Ann Int Med Den Res. 2016;2(3):137-8.

9. Sayanna S. Prevalence of inguinal hernia in Indian population: a retrospective study. Med Pulse Int Med Journal. 2015;2(2):75-8.

10. Basu I, Bhoj SS, Mukhopathyay AK. Retrospective study on prevalence of primary and recurrent inguinal hernia and its repairs in patients admitted to a tertiary care hospital. Indian Medical Gazette.2013:203-13.

11. Burcharth J, Pedersen M, Bisgaard T, Pedersen C, Rosenberg J. Nationwide prevalence of groin hernia repair. PLOS one. 2013;8(1):e54367.

12. Gulzar, MR, Iqbal J, Ulhaq MI, Afzal M. Darning vs bassini repair for inguinal hernia: a prospective comparative study. Professional Med J. 2007;14:128-33.

13. Ruhl CE, Everhart JE. Risk factors for inguinal hernia among adults in the US population. Am J Epidemiol. 2007;165:1154-61.

14. Nordback I. Side incidence of inguinal hernias. Ann Chir Gynaecol. 1984;73:87-90.

15. Sangwan M, Sangwan V, Garg M, Mahendirutta P, Garg U. Abdominal wall hernia in a rural population in India: is spectrum changing? Open J Epidemiology. 2013;3:135-8.

16. Devlin HB. Trends in hernia surgery in the land of Astley Cooper. In: Soper NJ, ed. Problems in general surgery Vol 12. Philadelphia, PA: Lippincott-Raven, 1995:85-92.

17. Garba ES. The pattern of adult external abdominal hernias in Zaria. Nigerian J Sur Res. 2000;2:12-5.

18. Mbah N. Morbidity and mortality associated with inguinal hernia in northwestern Nigeria. West African J Medicine. 2007;26:288-92.

19. Constance ER, James E. Risk factors for inguinal hernia among adults in the US population. American J Epidemiology. Am J Epidemiol. 2007;165(10):1154-61.

20. Lau H, Fang C, Yuen WK, Patil NG. Risk factors for inguinal hernia in adult males: a case-control study. Surgery. 2007;141:262-6.

21. Junge K, Rosch R, Klinge U, Schwab R, Peiper C, Binnebosel $\mathrm{M}$, et al. Risk factors related to recurrence in inguinal hernia repair: a retrospective analysis. Hernia. 2006;10:309-15.

22. Lowham AS, Filipi CJ, Fitzgibbons RJ, Stoppa R, Wantz GE, Felix EL, et al. Mechanisms of hernia recurrence after preperitoneal mesh repair traditional and laparoscopic. Ann Surg. $1997 ; 225: 422-31$.

Cite this article as: Balamaddaiah G, Reddy SVRM. Prevalence and risk factors of inguinal hernia: a study in a semi-urban area in Rayalaseema, Andhra Pradesh, India. Int Surg J 2016;3:1310-3. 